\title{
A challenging case of primary aldosteronism presenting in pregnancy
}

\author{
A Ghela, M Kashif, S Akhtar, S Howell, K Kaushal
}

Department of Endocrinology and Diabetes, Royal Preston Hospital, Lancashire Teaching Hospitals Foundation Trust, Preston, Lancashire

\section{INTRODUCTION}

- Primary aldosteronism (PA) is the most common form of secondary hypertension.

- PA is uncommonly diagnosed during pregnancy ${ }^{1}$.

- Uncontrolled blood pressure in pregnancy can result in adverse outcomes for both the mother and fetus ${ }^{1-4}$.

- Here we report a case presenting in pregnancy whose management proved particular challenging, due to variable compliance with therapy, frequent nonattendance at clinic, a subsequent pregnancy and negative imaging.

\section{CASE}

A 24 year old woman presented at 26 weeks gestation with severe pre-eclampsia, hypokalaemia $(2.1 \mathrm{mmol} / \mathrm{l})$ and a metabolic alkalosis.

- She received intravenous potassium replacement, labetalol and nifedipine

- She had to undergo an emergency caesarean section 3 days after admission.

- Investigation postnatally revealed a significantly raised aldosterone/renin ratio at $>12250$ (aldosterone $2450 \mathrm{pmol} / \mathrm{L}$, plasma renin activity $<0.2 \mathrm{pmol} / \mathrm{mL} / \mathrm{h}$ ).

- High dose oral potassium replacement was commenced alongside ongoing intravenous potassium.

Plasma aldosterone remained elevated (1580 pmol/l) following intravenous saline loading, confirming a diagnosis of PA. Spironolactone was commenced.

- $\mathrm{CT}$ and MRI scans showed normal adrenals.

- She remained hypokalaemic and hypertensive despite being prescribed spironolactone and oral potassium supplements; compliance was poor.

- She did not attend for further planned investigations and missed some clinic appointments.

Twelve months after initial presentation she became pregnant again. Spironolactone was stopped.

- She struggled with her potassium supplements due to vomiting and remained hypokalaemic. She was subsequently treated with amiloride and labetalol during pregnancy and delivered a healthy baby boy at nearly 34 weeks gestation following elective caesarean section.

- Postpartum, poor treatment compliance and missed visits to clinic continued.

- A dexamethasone suppression test excluded glucocorticoid remediable aldosteronism.

- Repeat adrenal imaging (MRI) was normal.

- Adrenal vein sampling (AVS) indicated right adrenal aldosterone excess.

- Right adrenalectomy was performed and a small adenoma identified.

- She has remained normotensive and normokalaemic off treatment postoperatively.

\section{INVESTIGATIONS}

\begin{tabular}{|c|c|}
\hline INVESTIGATION & RESULT \\
\hline $\begin{array}{l}\text { Aldosterone/renin } \\
\text { ratio }\end{array}$ & $>12250$ \\
\hline Aldosterone level & $2450 \mathrm{pmol} / \mathrm{L}$ \\
\hline Plasma renin activity & $<0.2 \mathrm{pmol} / \mathrm{ml} / \mathrm{h}$ \\
\hline $\begin{array}{l}\text { Plasma aldosterone } \\
\text { post saline loading }\end{array}$ & $1580 \mathrm{pmol} / \mathrm{L}$ \\
\hline $\mathrm{CT}$ & Normal adrenals \\
\hline MRI & Normal adrenals \\
\hline $\begin{array}{l}\text { Low dose } \\
\text { dexamethasone } \\
\text { suppression test }\end{array}$ & $\begin{array}{l}\text { Negative } \\
\text { Pre-Dexamethasone Aldosterone- } \\
799 \mathrm{pmol} / \mathrm{L} \\
\text { Post-Dexamethasone Aldosterone } \\
547 \mathrm{pmol} / \mathrm{L}\end{array}$ \\
\hline $\begin{array}{l}\text { Adrenal vein } \\
\text { sampling }\end{array}$ & $\begin{array}{l}\text { Right adrenal aldosterone excess } \\
\text { (right adrenal vein [RAV] } \\
\text { aldosterone: cortisol ratio } 245.4 \text {, } \\
\text { left adrenal vein [LAV] aldosterone: } \\
\text { cortisol ratio 3.6, Lateralisation } \\
\text { Index RAV: LAV 68.2) }\end{array}$ \\
\hline $\begin{array}{l}\text { Right adrenalectomy } \\
\text { \& histology }\end{array}$ & Adenoma \\
\hline
\end{tabular}

\section{DISCUSSION}

There are less than 50 case reports in the literature describing PA in pregnancy ${ }^{1-3}$.

Spironolactone is commonly used as a first line treatment for PA in non-pregnant patients but is not recommended during pregnancy, due to potential anti-androgenic effects causing ambiguous genitalia in males ${ }^{1-3}$.

The optimal management of PA during pregnancy is unclear. Initial pharmacological management should include antihypertensive drugs approved for pregnancy, along with potassium supplements. Eplerenone or amiloride can be considered as therapeutic options, although more evidence is needed regarding their safety and efficacy in pregnancy ${ }^{1-5}$.

PA increases the risk of maternal and fetal morbidity and mortality, including preterm delivery, placental abruption, intrauterine growth retardation, endorgan damage and stillbirth ${ }^{1-4}$. In our case, her first child had multiple medical issues.

The course of PA in pregnancy is variable, possibly in part due to the anti-mineralocorticoid effect of progesterone ${ }^{1-3}$.

The aim of management is to control blood pressure and normalise potassium levels.

For aldosterone-producing adenomas, laparoscopic adrenalectomy may occasionally need to be considered as a therapeutic option in the second trimester of pregnancy. Ideally, if pregnancy is planned, adrenalectomy should be performed pre-conception ${ }^{2,3}$.

This case also confirms the importance of AVS which identified unilateral aldosterone production despite normal imaging and enabled cure of her PA.

\section{REFERENCES}

1. Morton A (2015) Primary aldosteronism and pregnancy. Pregnancy Hypertens 5 (4), p 259-262

2. Landau E, Amar L (2016) Primary aldosteronism and pregnancy. Ann Endocrinol (Paris) 77 (2), p 148-160

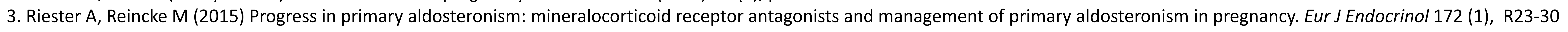

4. Krysiak R, Samborek M, Stojko R (2012) Primary aldosteronism in pregnancy. Acta Clin Belg 67 (2), p 130-134

5. Gunganah K, Carpenter R, Drake WM (2015) Epleronone use in primary aldosteronism during pregnancy. Clin Case Rep 4 (1), p 81-82 